\title{
1 nA BEAM POSITION MONITORING SYSTEM
}

JUU 17 Roagas Jefferson National Accelerator Facility, Newport News, VA 23693 USA

U S T, DOE/ER/40150--1139

A system has been developed at Jefferson Lab for measuring transverse position of very low current beams delivered to the Experimental Hall $B$ of the Continuous Electron Beam Accelerator Facility (CEBAF). At the heart of the system is a position sensitive cavity operating at $1497 \mathrm{MHz}$. The cavity utilizes a unique design which achieves a high sensitivity to beam position at a relatively low cavity $\mathrm{Q}$. The cavity output RF signal is processed using a down-converter and a commercial lock-in amplifier operating at $100 \mathrm{kHz}$. The system interfaces with a VME based EPICS control system using the IEEE 488 bus. The main features of the system are simple and robust design, and wide dynamic range capable of handling beam currents from $1 \mathrm{nA}$ to $1000 \mathrm{nA}$ with an expected resolution better than $100 \mu \mathrm{m}$. This paper outlines the design of the system.

\section{INTRODUCTION}

The Thomas Jefferson National Accelerator Facility, or Jefferson Lab, is a basic research laboratory built to probe the nucleus of the atom to learn more about the quark structure of matter. The underground recirculating accelerator uses superconducting radio-frequency technology to drive electrons to energies between $800 \mathrm{MeV}$ and $4 \mathrm{GeV}$. The electron beam can be split for use by three simultaneous experiments in the end stations.

The middle one of the three experimental stations, hall $B$, requires beam currents in the range from $1 \mathrm{nA}$ to $1000 \mathrm{nA}$. A new BPM system was needed to accommodate beam position measurements at such low currents. We selected a system using position sensitive resonant cavities as pickups and phasesensitive synchronous demodulators. The project started in January 1996.

\section{SYSTEM OVERVIEW}

\begin{tabular}{|l|l|}
\hline Number of BPMs & 3 \\
\hline Beam Energy & $800 \mathrm{MeV}-4 \mathrm{GeV}$ \\
\hline Operating Range & $1 \mathrm{nA}-1000 \mathrm{nA}$ \\
\hline $\begin{array}{l}\text { Parameters to be } \\
\text { Measured }\end{array}$ & $\mathrm{x}$ and y positions, current \\
\hline $\begin{array}{l}\text { Nominal Measuring Rate } \\
\text { out of control system }\end{array}$ & 1 orbit/s \\
\hline $\begin{array}{l}\text { Position Measuring } \\
\text { Range }\end{array}$ & $|\mathrm{x}|,|\mathrm{y}| \leq 5 \mathrm{~mm}$ \\
\hline Absolute Accuracy & $\leq 1 \mathrm{~mm}$ \\
\hline
\end{tabular}

" Work supported by DOE contract DE-AC03-84-ER40130.

\begin{tabular}{|l|l|}
\hline Resolution & $\leq 100 \mu \mathrm{m} @ 1 \mathrm{nA} \mathrm{CW}$ \\
\hline Linearity Within & $\partial \mathrm{x} / \mathrm{x} \leq 10 \%$ \\
Measuring Range & $\partial \mathrm{y} / \mathrm{y} \leq 10 \%$. \\
\hline Current Dependence & $\leq 50 \mu \mathrm{m}$ peak-peak \\
& $\begin{array}{l}@ \text { required current } \\
\pm 50 \%\end{array}$ \\
\hline Stability, Drift & $\leq 25 \mu \mathrm{m}$ rms in 8 hours \\
\hline
\end{tabular}

Table 1: System specifications.

Concept selection was the most difficult part of this project. We searched at Jefferson Lab as well as at other laboratories and industry for alternative concepts that would give us a good starting point.

At the time the project started, CEBAF was equipped with a Switched Electrode Electronics BPM system (SEE) covering dynamic range from $1 \mu \mathrm{A}$ to $1000 \mu \mathrm{A}$ [1]. Our plan was to design 30 times more sensitive beam pick-ups and 30 times more sensitive electronics to make a BPM system that works down to $1 \mathrm{nA}$. However, we soon realized, that we can modify the SEE to increase its sensitivity by factor 5 but no more. The key limitation of the system was a quasisynchronous demodulator around which the electronics was built. The problem does not lie in the particular circuit that we use, but in the quasi-synchronous demodulation concept, where signal to be demodulated is also used to generate a demodulation carrier. A phase-sensitive demodulation scheme appeared to be the only feasible solution for electronics. A similar system that uses phase-sensitive synchronous demodulation is operational at Mainz Microtron in Germany [2]

A position sensitive resonant cavity came at the top of our list among alternatives for beam pick-ups. It was the only type of pick-up that promised an increase in position sensitivity by factor of approximately 30 with respect to the wireline BPMs used at CEBAF accelerator [3]. We evaluated different resonant cavity configurations: circular, rectangular, off-centered TM010. We selected a design that is conceptually similar to the RF separator cavity design used at CEBAF to split electron beam to three experimental halls [4]. This position sensitive cavity, explained in detail below, gives approximately $10 \mathrm{~dB}$ greater position sensitivity than circular TM110 cavity.

Figure 1 shows a system block diagram. A position measurement is done by taking the signal from a position sensitive cavity ( $x$ or $y$ ) and normalize it with the one from a current cavity. To get $x, y$ positions and beam current we need three dedicated electronic channels. 


\section{DISCLAIMER}

This report was prepared as an account of work sponsored by an agency of the United States Government. Neither the United States Government nor any agency thereof, nor any of their employees, make any warranty, express or implied, or assumes any legal liability or responsibility for the accuracy, completeness, or usefulness of any information, apparatus, product, or process disclosed, or represents that its use would not infringe privately owned rights. Reference herein to any specific commercial product, process, or service by trade name, trademark, manufacturer, or otherwise does not necessarily constitute or imply its endorsement, recommendation, or favoring by the United States Government or any agency thereof. The views and opinions of authors expressed herein do not necessarily state or reflect those of the United States Government or any agency thereof. 


\section{DISCLAMIER}

Portions of this document may be illegible in electronic image products. Images are produced from the best available original document. 


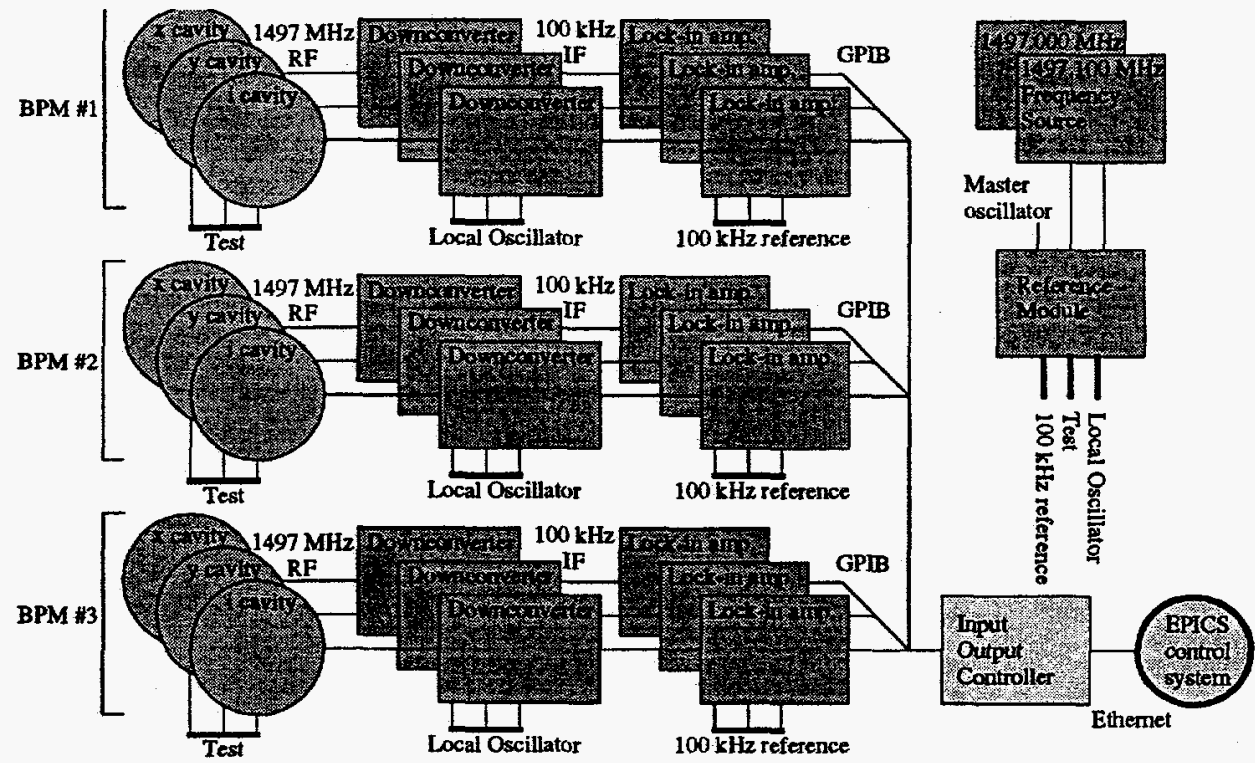

Figure 1: $1 \mathrm{nA}$ BPM system block diagram.

\section{POSITION CAVITY}

Information about the beam is provided to the electronics by three room temperature RF cavities operating at the third harmonic of the $499 \mathrm{MHz}$ bunch frequency. Two of the cavities are position monitors with one producing an $X$ position $X$ current signal and the other a $Y$ position $x$ current signal. The third cavity is a CEBAF Beam Current Monitor [5] that provides beam current and phase information necessary for position signal amplitude scaling and sign correction.

\begin{tabular}{|l|l|}
\hline Bunching Frequency & $499 \mathrm{MHz}$ \\
\hline $\begin{array}{l}\text { Beam Line Aperture } \\
\text { Restriction }\end{array}$ & $\begin{array}{l}3.0 \mathrm{~cm} \text { diameter } \\
\text { minimum }\end{array}$ \\
\hline BPM Resolution & $\begin{array}{l}70 \mathrm{pV} / \mu \mathrm{m}(-150 \mathrm{dBm} @ \\
100 \mu \mathrm{m}) @ 1 \mathrm{nA}\end{array}$ \\
\hline $\begin{array}{l}\text { Longitudinal Beam Line } \\
\text { Space }\end{array}$ & $90 \mathrm{~cm}$ maximum \\
\hline Position measuring range & $\mid \mathrm{xl}, \mathrm{ly} \leq 5 \mathrm{~mm}$ \\
\hline Resonant Frequency & $1497 \mathrm{MHz}$ \\
\hline Loaded Q & 3500 \\
\hline Diameter & $19.0 \mathrm{~cm}$ \\
\hline Depth & $9.5 \mathrm{~cm}$ \\
\hline Rod Gap & $3.0 \mathrm{~cm}$ \\
\hline Material & $\begin{array}{l}\text { Copper Plated Stainless } \\
\text { Steel }\end{array}$ \\
\hline
\end{tabular}

Table 2. Position cavity specifications.

The position cavity is a new design that offers excellent position sensitivity (resolution), transverse mode isolation and stability. The cavity is a pillbox with field perturbing rods operating in a dipole type mode (see figure 2). Resolution is defined here as the ratio of the change in the cavity output signal voltage divided by the change in the beam position for a given current. The longitudinal electric field of the mode goes through a null point (and sign reversal) in the center of the cavity resulting in a shunt impedance of zero and no output signal for a centered beam. The position cavity is designed to measure accurately beams that travel through a one centimeter square window centered on the cavity axis. Inside this window the electric field amplitude changes linearly with position and the resolution is at its highest value.

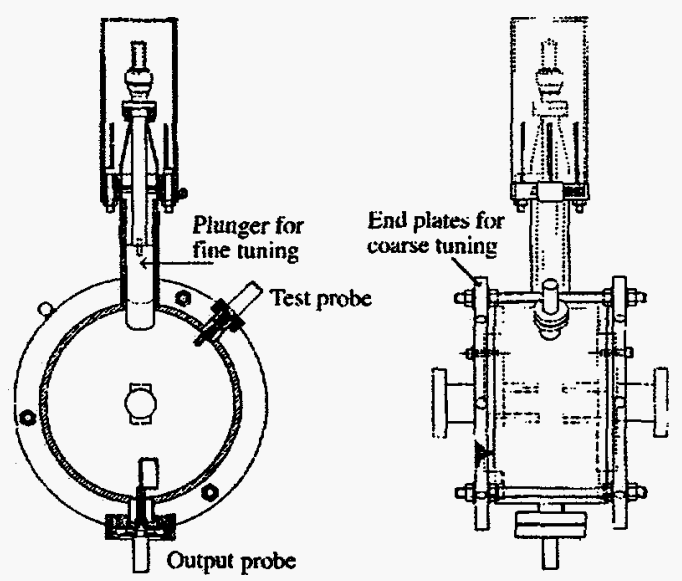

Figure 2. Position cavity front and side view.

Placing rods within the cavity draws the electric field maxima locations of the mode closer to the cavity axis. This field redistribution increases the resolution by a factor of 2.5 compared to a cavity with no rods (see figure 2). The rods also have a polarizing effect in the cavity, locking the orientation of the fields and eliminating the transverse mode. This improves the $x-y$ isolation and permits greater overall system accuracy. The rods also introduce more loss and the $\mathrm{Q}$ of the mode is reduced by half. Resulting broader resonance is then beneficial in reducing drifts for improved long term measurement stability. 


\section{ELECTRONICS}

A separate electronics package processes the $1497 \mathrm{MHz}$ radio frequency (RF) signal coming from each cavity. Nine equivalent electronic channels use phase-sensitive demodulators to digitize and extract amplitude and phase of the signals.

\begin{tabular}{|l|l|}
\hline Operating Frequency & $1497 \mathrm{MHz}$ \\
\hline Dynamic Range & $-156 \mathrm{dBm}$ to $-40 \mathrm{dBm}$ \\
\hline Demodulation scheme & IF sampling, digital I-Q \\
\hline Dynamic reserve & $100 \mathrm{~dB}$ \\
\hline Stability, Drift & $\leq 0.5 \% \mathrm{~ms}$ in 8 hours \\
\hline Channel-channel isolation & $55 \mathrm{~dB}$ \\
\hline Baseband time constant & $10 \mu \mathrm{s}-10 \mathrm{~s}$ \\
\hline Testing capabilities & $\begin{array}{l}\text { Frequency sweep } \\
1 \mathrm{MHz}\end{array}$ \\
\hline
\end{tabular}

Table 3: Electronics specifications.

The $1497 \mathrm{MHz}$ signal from each cavity is first amplified in a low noise amplifier, mixed with a $1497.1 \mathrm{MHz}$ local oscillator (LO) signal in a dualbalanced mixer and then low pass filtered. This yields an IF frequency signal of $100 \mathrm{kHz}$ that can be processed by a lock-in amplifier; the latter sets the limit on to how high the IF frequency can be. The lockin amplifier is a commercial off-the-shelf model 7200 available form AG\&G. This DSP based instrument samples $100 \mathrm{kHz}$ signal and demodulates it in a numerical (DSP) I-Q demodulator using an externally supplied $100 \mathrm{kHz}$ reference. Use of the digital demodulator significantly improves the accuracy, stability and flexibility of the system.

The $100 \mathrm{kHz}$ reference, LO and $1497 \mathrm{MHz}$ test signals are generated by a reference frequency module. The $100 \mathrm{kHz}$ reference is generated by mixing 1497.1 MHz signal form the LO frequency source with a $1497 \mathrm{MHz} \mathrm{RF}$ signal received from the CEBAF machine master oscillator. It was a design challenge to generate a $1497.1 \mathrm{MHz}$ LO signal with minimum content of $1497 \mathrm{MHz}$ RF signal. It turns out that $1497 \mathrm{MHz}$ signal in the LO channel limits system performance at the lower signal levels; a weak 1497 $\mathrm{MHz}$ signal in the LO path enters the mixer in a downconverter module, where it couples to the RF port of the mixer and gets reflected back to the RF port. This process generates an unwanted $100 \mathrm{kHz}$ signal. This phenomenon can be easily observed by terminating the downconverter input to $50 \Omega$ and taking a reading from the lock-in amplifier. This explains use of isolators in LO and RF signal paths.

The connection to the CEBAF EPICS [6] control system is a dedicated input output controller (IOC). Each lock-in amplifier communicates with and is controlled by that IOC via a GPIB bus. Our estimate is that bandwidth of the GPIB bus will permit obtaining 10 readings of all lock-in amplifiers per second which is 10 times faster than is required.

The system is to be installed in the transport line tunnel close to the cavities to minimize signal loss due to cable attenuation. A modular design was chosen to facilitate maintenance and minimize time to repair in case of a failure. The modules conform to $3 \mathrm{U}, 220 \mathrm{~mm}$ Eurocard standard and use DIN type $M$ connectors with $R F$ inserts.

\section{SUMMARY}

The system is to be installed in September 1997. Cavities are under construction. We have tested electronics in our laboratory. The measured sensitivity of the system is $-156 \mathrm{dBm}$ and the worst case channel to channel isolation greater than $55 \mathrm{~dB}$. We now plan to install the system in the tunnel and repeat the measurements to check performance in situ since a system with such a high sensitivity is more susceptible to any externally generated interference.

\section{ACKNOWLEDGMENTS}

Jean-Claude Denard helped us identify customer needs and provided encouragement and technical support. Ron Sundelin was the ultimate source of the suggestion to consider a design similar to separator cavity. This work was supported by the U.S. DOE under contract number DE-AC05-84ER40150.

\section{REFERENCES}

[1] T. Powers et al.: 'Design, Commissioning, and Operational Results of Wide Dynamic Range BPM Switched Electrode Electronics', Proceedings of the Seventh Beam Instrumentation Workshop, Argone Il, (AIP conference proceeding 390)

[2] H. Euteneuer: 'Beam Monitors at the Mainz Microtron', have a copy of the paper but don't know the reference.

[3] W. Barry: 'A General Analysis of Thin Wire Pickups for High Frequency Beam Position Monitors', Jefferson Lab PR 90-024, October 1990.

[4] C. Hovater et al.: "The CEBAF' RF Separator System', Proceedings of the XVIII International Linear Accelerator Conference, 26-30 August 1996, Geneva, Switzerland

[5] R. Ursic et al.: 'CEBAF Beam Loss Accounting' Proceedings of the 1995 Particle Accelerator Conference, Dallas, TX

[6] http://www.cebaf.gov/accel/documents/ epics_doc.html 